\title{
Soft Skills: What do Computing Program Syllabi Reveal About Non-Technical Expectations of Undergraduate Students?
}

\author{
Wouter Groeneveld \\ KU Leuven \\ Leuven, Belgium \\ wouter.groeneveld@kuleuven. be
}

\author{
Brett A. Becker \\ University College Dublin \\ Dublin, Ireland \\ brett. becker@ucd.ie
}

\author{
Joost Vennekens \\ KU Leuven \\ Leuven, Belgium \\ joost. vennekens@kuleuven. be
}

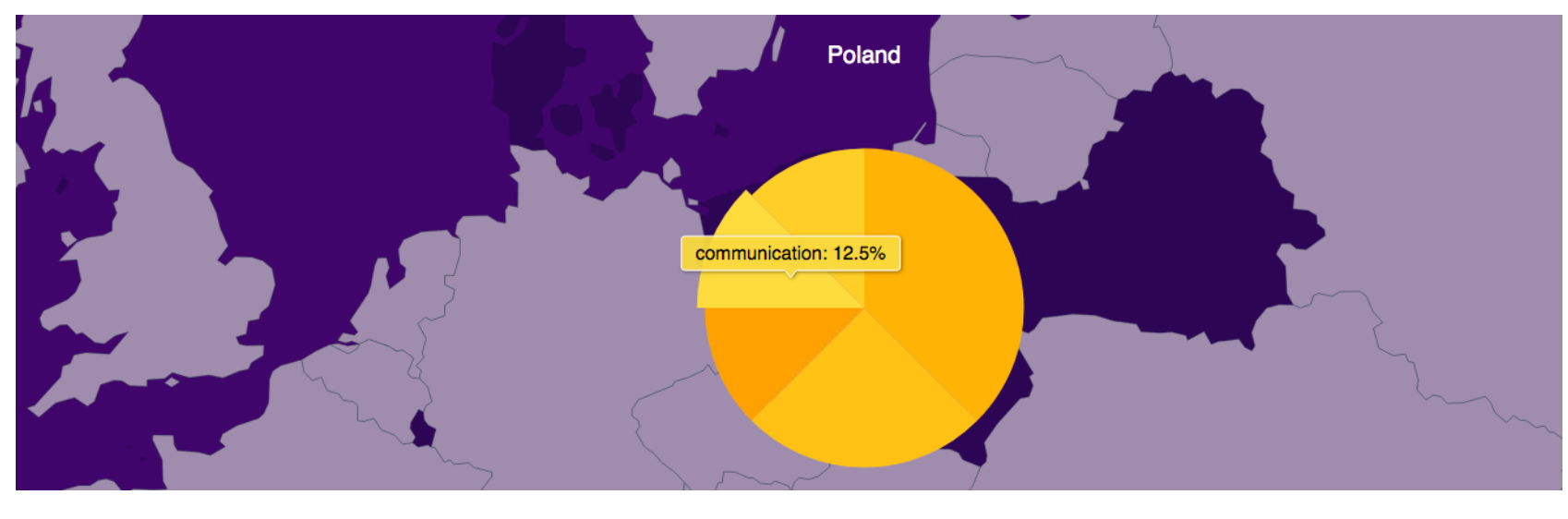

Figure 1: An interactive colour-coded map showing non-technical course categories in Polish universities. Our interactive data exploration tool is publicly available at https://people.cs.kuleuven.be/ wouter.groeneveld/courses/.

\begin{abstract}
Industry expectations of computing graduates are higher than ever. Not only are candidates required to be highly skilled in a variety of technologies, but they also need to come equipped with non-technical skills - often called soft skills or professional skills. This puts a lot of pressure on computing programs, as educators try to integrate these requirements into already full curricula. Despite the fact that incorporating some of these skills into programs is seemingly common practice, little is known about what skills are being taught and why, outside of isolated case studies. In this research, we ask: What non-technical skills are expected of undergraduate students according to computing programs? To answer this we manually curated 278 non-technical course syllabi from 110 universities in 30 European countries. We then analysed them to identify trends and expose gaps. The most frequently identified skills are teamwork, ethics, written/oral communication, and presentation skills, while the development of one's own values, motivating others, creativity, and empathy feature least frequently. By providing a detailed analysis and an interactive website visualising this data, we hope to aid the community in reviewing which non-technical skills are taught with an aim to teaching the right skills to the right students. This work sheds new light on recent trends in what is expected of undergraduate computing students in terms of non-technical skills and identifies areas where more coverage might be needed.
\end{abstract}

\section{Introduction}

In addition to the acquisition of technical knowledge such as programming languages and algorithmic design, undergraduate students are also expected to learn non-technical skills such as a sense of responsibility and working effectively in a team. Software development is no longer perceived by industry veterans purely as a cognitive act, but as a broader group of both technical knowledge and non-technical skills Li et al. (2015). It 
has also been stated recently that industry regularly questions the work-readiness of graduates, and in some cases companies can be less concerned about technical skills than 'soft' skills needed for team based, customer focused business environments Stevens and Norman (2016). This situation is not solely driven by industry expectations, however. According to a recent study by Kinnunen et al., that fathoms initial undergraduate expectations, incoming computing students seem to assume that thev will not only master technical knowledge, but also learn about professional 'non-technical' skills Kinnunen et al. (2018).

Educational institutions have responded by integrating these skills into curricula. However, unlike more technical courses, the structuring and inclusion of non-technical courses is not very uniform between institutions. For instance, there is no CS1 Hertz (2010) for soft skills. Nonetheless, such skills have been highlighted as important for some timeLópez et al. (2007) and the ACM/IEEE Computing Curricula 2001 Project (CC2001) included Professional Practice as one of its 11 principles (on Computing Curricula, 2001, p 13):

CC2001 must include professional practice as an integral component of the undergraduate curriculum. These practices encompass a wide range of activities including management, ethics and values, written and oral communication, working as part of a team, and remaining current in a rapidly changing discipline.

CS2008, which was an update of CC2001, found "Communication and other transferable skills had to be addressed" (on Computing Curricula, 2008, p 11). However, only one unit was added with relatively little refinement in this direction. CS2013 Joint Task Force on Computing Curricula and Society (2013) though, addressed much of what we consider to be soft skills head on, as discussed in Section 2.

So far we have not found any study that investigates computing syllabi to see which skills are effectively taught and which still require more attention, specifically for non-technical abilities. There is a plethora of publications on industry expectations, case studies in education, and the so-called mismatch between industry desires and educational delivery. We would like to look beyond success stories and effectively identify nontechnical skills based on available information in learning outcomes. At SIGCSE 2019, Becker and Fitzpatrick presented a paper that determined what educators expect of introductory programming students, by analysing learning outcomes from CS1 syllabi Becker and Fitzpatrick (2019). This inspired us to build on that methodology to extract non-technical expectations from computing programs. We formulated the following research questions:

- Q1: Which skills are taught in undergraduate computing courses, according to their learning outcomes?

- Q2: What types of non-technical courses are included in undergraduate computing programs?

- Q2b: What percentage of these courses are compulsory, in what year are they offered, and what percentage of them have explicit learning outcomes mentioning soft skills?

The remainder of this paper is organised as follows. Section 2 reviews related work on identifying nontechnical abilities. In Section 3 we present our methodology. In Sections 4 and 5, we present and discuss results, followed by possible limitations in Section 6 before concluding in Section 7.

\subsection{What Exactly is a Soft Skill?}

Matteson et al stated: "We universally recognise that soft skills are important, but when pressed to describe particular soft skills, the concept becomes murky" (Matteson et al., 2016, p. 71). In this work we use the following working concept of a soft-skill, acknowledging the myriad difficulties with attempting to define such a concept succinctly:

A soft skill is a non-technical skill that can be learned in a traditional academic setting and is relevant to proficiency in a given field of study, which may itself be largely technical.

This is not to say that soft skills are not related to technical skills. Communication for instance is arguably a soft skill given the definition above, but in computing, a desirable soft skill may be communicating technical knowledge to a lay audience, thus requiring technical knowledge in order to apply the non-technical soft skill. Further, the definition of skill we use in the above is also provided by Matteson et al. Matteson et al. (2016):

Skill: The ability to access knowledge from a domain-specific knowledge base and use that knowledge to perform an action or carry out a task.

The following definitions of dispositions, attitudes, beliefs, and values provided by Matteson et al. are also used. Any trait that fits one of these definitions is therefore not a skill, and cannot be a soft skill.

- Dispositions: Individual qualities, relatively stable over time, that influence behaviour and actions performed as part of an individual's skill set.

- Attitudes: A positive or negative judgement, based in part on emotion, about an outside entity.

- Beliefs: An acceptance that certain factual evidence is true, informed by an individual's own values.

- Values: General standards or principles that guide behaviours among varying situations and to which individuals feel a strong commitment. 


\section{Related Work}

\subsection{From the Literature}

Searching the ACM Digital Library Full-Text Collection for 'soft skills' returns 165 articles dating from 2000. Since then these skills have been featured in venues such as ACM Transactions on Computing Education Hundhausen et al. (2013) and Communications of the ACM Joseph et al. (2010). This section reviews a selection of this work to situate our work in this wider literature.

Aasheim et al. conducted a survey that highlighted the perceived gap between skills required by industry and those taught to students Aasheim et al. (2012). Their results are based on a survey conducted in the United States targeting IT managers. They compiled a list of dozens of "Skills / Traits / Knowledge Areas" that spanned technical skills, soft skills, and even personality traits such as honesty. Those that can be considered soft skills given our discussion in Section 1.1 are shown in Table 1 .

Table 1: Non-technical soft skills identified in a U.S. survey of 310 IT managers. From Aasheim et al. (2012).

\begin{tabular}{lr}
\hline Skill & Rank \\
\hline Communication (oral and written) & 4 \\
Analytical skills & 5 \\
Professionalism & 6 \\
Ability to work in teams & 7 \\
Flexibility/adaptability & 8 \\
Interpersonal skills & 10 \\
Creative thinking & 11 \\
Organizational skills & 12 \\
Knowledge of primary business functions & 24 \\
Leadership skills & 29 \\
Relevant academic research experience & 44 \\
\hline
\end{tabular}

The top soft skill in Table 1 is communication (oral and written). The top three are not skills as per Section 1.1: honesty, attitude, and willingness to learn new skills. The fact that 27 of 48 skills were "nontechnical' including the top 14, and that 6 of the top 10 are soft skills (in addition to being non-technical) highlights a strong requirement for soft skills in industry. These results were also compared with an earlier study Aasheim et al. (2009). Other than identifying 17 new skills, the rankings of all skills in both studies did not change substantially.

In 2016, Stevens and Norman examined 543 IT job ads in the Wellington, New Zealand area. They also interviewed 26 industry participants between 2 and 50 years of experience and conducted two focus groups consisting of industry, academic and government participants Stevens and Norman (2016). They found that industry tends to look for 'base-level' technical skills and make hiring decisions on more personal qualities. leaving detailed job-specific knowledge to on-the-job training. Their findings were summarised as (Stevens and Norman, 2016, p. 1): (1) Tertiary education providers are not typically expected to teach specific technologies in the face of rapid innovation and industry change; (2) Soft skills contribute significantly to many job requirements and most employers consider these soft skills to be un-trainable in the work-place, making soft skills a critical hurdle for employment; and (3) Short term pressure on employers for technical skills can result in the need for soft skills being overlooked.

Stevens and Norman found that $40 \%$ of job ads specified 0 or 1 soft skill, and $60 \%$ specified 2 or more. Thev identified 8 soft skills that were specified by the $60 \%$ that specified 2 or more soft skills as shown in Table 2 . Like the Aasheim et al. study Aasheim et al. (2012), some of these are not considered skills, and were therefore omitted from Table 2 .

Table 2: Soft skills desired from industry in IT graduates and the percentage of job ads mentioning them. From Stevens and Norman (2016).

\begin{tabular}{lr}
\hline Skill & $\%$ \\
\hline Communication, written and verbal & $\sim 73$ \\
Proactive, self-motivated, autonomous & $\sim 52$ \\
Team player, collaborative & $\sim 39$ \\
Service, outcome or client focus & $\sim 34$ \\
Relationship, interpersonal skills & $\sim 26$ \\
Leadership & $\sim 4$ \\
Internal/external stakeholder management & $\sim 4$ \\
\hline
\end{tabular}


Stevens and Norman also surveyed job ads seeking experienced applicants in addition to graduates . One additional soft skill - acting as a mentor - was desired of experienced applicants and not of graduates. Stakeholder management and leadership also featured more prominently (just over $20 \%$ ) compared to $\sim 4 \%$ for graduate ads. For the remaining six skills in Table 2, percentages for experienced staff differed but followed a similar trend as in Table 2.

In total, Stevens and Norman identified 294 soft skills, grouped into eight categories: communication; interpersonal skills; managing yourself; attitude: aptitude; understand business drivers; teamwork; and cultural fit. Like the Aasheim et al. study Aasheim et al. (2012), Stevens and Norman found communication to be the top soft skill in job ads as well as in interviews and focus groups. Teamwork also featured in both studies along with interpersonal skills. Zhang et al. conducted a study on practising and evaluating soft skills in IT capstone projects and found both communication and teamwork mentioned as two of the five most listed soft skills in student feedback Zheng et al. (2015).

In 2019, Groeneveld et al. Groeneveld et al. (2019) performed a systematic literature review on the teaching of non-technical skills in computing education, concluding that again communication, teamwork, self-reflection, and conflict resolution are popular skills to teach students.

\subsection{Accreditation Recommendations}

ABET specifies five 'Student Outcomes' in their Criteria for Accrediting Computing Programs 2019-2020 ABET (2018), of which three can be considered soft skills:

- Communicate effectively in a variety of professional contexts

- Recognise professional responsibilities and make informed judgements in computing practice based on legal and ethical principles

- Function effectively as a member or leader of a team engaged in activities appropriate to the program's discipline

It is worth noting that again, communication and teamwork are mentioned. The ACM/IEEE CC2001 Project mentioned in Section 1 included Social and Professional Issues (SPI) as the $7^{\text {th }}$ largest of 14 core topics. CS2008 on Computing Curricula (2008) added one unit to SPI: Security Operations. However, CS2013 Joint Task Force on Computing Curricula and Society (2013) for the first time specifically mentioned soft skills, and an increased importance of social issues and professional practice. These guidelines removed several old units and added Professional Communication and Sustainability.

The work on soft skills also extends well beyond computing into many, if not all academic disciplines. Indeed, the move towards graduate attributes encompasses what are often referred to as soft skills. Barrie sees these principles as being supported by the development of skills and abilities in five key clusters: Research and inquiry; Information literacy: Personal and intellectual autonomy; Ethical, social and professional understanding; and Communication Barrie (2012).

Having established that non-technical skills are important and that model curricula encourage their inclusion in computing programmes, the question remains: How are these skills best incorporated into specific computing curricula?

Purao and Suen (Purao and Suen, 2010, p. 88) wrote:

A recurring theme in prior work is the definition of 'soft skills' as something different from 'hard skills' [citing Rumberger (1989)]. Whereas the latter are considered to be a specific to a task (e.g. Programming or Design), the former represent a broad array of interpersonal and social behaviours, habits and inclinations that allow an individual to engage with a larger number of social situations effectively. Accreditation boards such as ABET and AACSB as well as organisations such as the US Department of Labor emphasise these needs to educate students with soft skills.

They performed a literature meta-analysis and came up with a list of soft-skills including team work, but not explicitly communication. They then developed a data-driven discovery of soft-skills using students who had completed at least one internship and were enrolled in a course where the major learning vehicle was a termlength industry-sponsored systems development project that required interaction with a client. Their discovery resulted in 14 soft skills, again mentioning teamwork but not explicitly communication.

\subsection{Summary}

All of the sources in this section discuss soft skills in job ads, interviews, other literature (and are thus secondary sources), or accreditation and curricular guidelines. All sources mention communication and teamwork skills as important other than Purao and Suen Purao and Suen (2010) (teamwork only) and Barrie Barrie (2012) (communication only). This work seeks to extract skills directly from curricula in search of answers to our research questions, and to compare our findings to those explored here. 


\section{Methodology}

The methodology was adapted from Becker and Fitzpatrick Becker and Fitzpatrick (2019), who mined the 2016 QS World University Rankings® for Introductory Programming syllabi. A similar procedure was adopted, tailored for the aims of this paper. We manually populated a database of 278 non-technical courses in 110 computing programs spread over 30 European countries. All institutions were derived from the 2019 QS World University Rankings®, sorted by ranking, filtered on Europe. Countries not present in this list were not processed.

We deliberately narrowed down our search to only include European institutions for several reasons. First, we wanted to avoid introducing unintended bias - for instance by leading American universities which have a heavy presence in rankings.

Second, the Bologna accord Fuller et al. (2006), which most European countries are signatory to, ensures minimal equality between universities and the guarantees that courses (modules in Bologna terms) are based on explicitly stated learning outcomes, along with course weights expressed in ECTS (European Credit Transfer and Accumulation System). As evidence that this can affect searches such as ours, Becker and Fitzpatrick found that their global search of syllabi, looking for learning outcomes, were skewed towards European Universities. Specifically they found more explicitly stated learning outcomes in syllabi from European countries. As the skills we are investigating are intricately related to learning outcomes, it is possible that these skills are reported more explicitly and more often than in other jurisdictions, due to the Bologna accord.

Third, we wanted a relevant and appropriately scaled data set. Since the authors are affiliated with European universities, they are more familiar with the European system. Since one of the authors can read four European languages, navigating websites became much easier. We strongly believe that this methodical approach is representative enough to reliably answer our research questions in Europe, and also to provide a basis for comparison to other regions in the future.

During a feasibility study, we initially catalogued universities from United Kingdom, of which promising results encouraged us to continue populating the database. Since $30 \%$ of UK universities were covered, this coverage rate (rounded down) became the target for all other listed countries. However, some universities could not be included due to problems with data retrieval (detailed course content unavailable, broken links, no computing undergraduate degree offered, no pure computing curriculum found). Whenever possible, the next university for that country has been included in the database, to maintain the intended cover ratio.

We believe that a similar methodology could be applied to a global survey but there would be several issues that may complicate the interpretation of findings including language barriers, the effects of different educational svstems, and bias towards certain areas (such as the USA). Just as we found the New Zealand Stevens and Norman (2016) and American Aasheim et al. (2009, 2012) studies to be helpful, we believe that a European-wide study will be beneficial to others.

\subsection{Non-technical Course Database Population}

CS syllabi were searched using the following steps:

(1) On the institution website, locate the undergraduate computing information page, possibly located on the faculty site, or on the general program site. If the English website is incomplete, interpret the native language or use Google Translate.

(2) Scan module lists and identify non-technical courses. Navigate to each such course syllabus and extract data.

(2b) If no syllabus link was found, perform a Google search for (course identifier) + (university name). If this second attempt fails, exclude the university.

Identification of non-technical courses was done by excluding everything that is related to the theoretical, technical, and cognitive aspects of CS. For example, Aalto University in Finland offers a bachelor in Data Sciencel, of which the curriculum contains typical courses such as 'Matrix algebra', 'Programming 1', 'Databases', and 'AI' that are not of interest for our study, while courses entitled 'Creative Coding', 'Introduction Course for Bachelor Students', 'Introduction to Digital Business and Venturing', and 'Professional Development' were selected for inclusion.

Since we wanted to focus first and foremost on CS, only pure full-time undergraduate (bachelor) computing curricula were considered, excluding majors in engineering or science with minors in IT. Double degree programs such as Oxford's Computer Science and Philosophy were also not taken into consideration. The following modules were also ignored: bachelor thesis, part-time courses, optional courses with course lists from other faculties, industrial placement or internships.

\footnotetext{
${ }^{1}$ https://into.aalto.fi/display/enbsctech/Data+Science+2018-2020
} 
The following data was extracted from the syllabus link, whenever possible: university name, program name, course name, URL, year, optional, credits, learning outcomes. and ECTS Credits. Learning outcomes were saved together with an English translation using Google Translate if required. Included courses were divided into the following colour-coded categories, as shown in the pie chart from Figure 1: art/creativity (1), coaching (2), business (3), professional skills (4), humanities (5), project-related (6), communication (7), and seminars $(8)$.

\subsection{Identifying Skills in Learning Outcomes}

Course records were manually tagged with skills found in the learning outcomes. For example, if the learning outcome stated:

During the semester, students are required to work in teams to promote communication skills. At the end of this course, students should be able to: present their findings to an audience, and reflect upon their work.

That Then the following skills were tagged: 'teamwork', 'communication', 'presentation skills', 'self-reflection', while maintaining the original wording as much as possible. It is important to note that due to the ambiguity of these skills, some generalisations had to be made. Ambiguous terms such as 'responsibility' and 'accountability' have been grouped together. Courses without learning outcomes were not tagged. If learning outcomes explicitly mention skills beside cognitive knowledge, then the course will be tagged as explicit.

To ensure the correctness of the identified skills, a cross-validation step was carried out, comparing and correcting data where needed. Due to the low number of differences and differing language abilities of the authors, no inter-rater reliability was calculated. We feel that this is justified due to the hand-curated nature of this study, and due to the large number of categories and other 'hard' course facts (like the amount of credits) that were collected.

\section{Results \& Discussion}

We manually populated a database of 278 non-technical courses in 110 computing programs spread over 30 European countries, covering at least 30\% of the universities for each European country in the 2019 QS World University Rankings@. If a given country only had one university we always included that. However, due to problems with data retrieval, we excluded the following numbers of institutions for the listed reasons. In each case where an institution was excluded, the next institution from the same country was used as a replacement.

- No (pure) computing curriculum found (7)

- No computing undergraduate degree offered (6)

- No detailed course catalogue found (29)

- Website unreachable (1)

Thus $41 \%$ of the first encountered universities were excluded (and replaced). These are available on our website. This is better than the exclusion rate of Becker and Fitzpatrick, who excluded $77 \%$ of the universities they looked to include in their study. It is likely that their exclusion rate was higher than ours as they were searching for a specific course (albeit introductory programming being an extremely common one). It is also probable that they had more language difficulties than we had. Below is a summary of the institutions included in our study.

- Countries included: Austria, Belgium, Bosnia and Herzegovina, Croatia, Czech Republic, Denmark, Estonia, Finland, France, Germany, Greece, Hungary, Ireland, Italy, Latvia, Lithuania, Netherlands, Norway, Poland, Portugal, Romania, Russia, Serbia, Slovakia, Slovenia, Spain, Sweden, Switzerland, UK, Ukraine.

- QS World University Rankings® [highest, lowest]: 5, 801-1000 (Lower rankings are aggregated into ranges.)

- Number of courses per institution [mean (SD)]: 2.52 (1.43)

- Percentage of universities in each country [min, max]: 15\% (Russia), 100\% (Bosnia and Herzegovina, Croatia, Serbia). Due to data retrieval issues listed above, $80 \%$ of the countries met the $30 \%$ inclusion ratio.

\subsection{RQ1: Which skills are taught?}

Our first research question was: Which skills are taught in undergraduate computing courses, according to their learning outcomes?

Table 3 shows all identified soft skills, occurring in more than $5 \%$ of courses (278 courses total). This includes 17 of 50 skills total. The full list of skills can be found at the website.

Communication and teamwork are the top two soft skills, with $47.1 \%$ and $34.2 \%$ of courses including them. This largely agrees with the literature and curricular recommendations we reviewed in Section 2. Other skills 
agreed with prior work in being less frequent. For instance, leadership was mentioned in $6.1 \%$ of the courses we surveyed, ranked 29/48 by Aasheim et al. Aasheim et al. (2012) and featured in $\sim 4 \%$ of job ads for Stevens and Norman Stevens and Norman (2016).

Surprisingly however, several skills that ranked highly in the work we reviewed in Section 2 featured very infrequently in our search. For example, interpersonal skills were mentioned in only $2.5 \%$ of the courses we surveyed, but was ranked $10 / 48$ by Aasheim et al. Aasheim et al. (2012) and in $26 \%$ of job ads surveyed by Stevens and Norman Stevens and Norman (2016). Another striking difference is 'Creative thinking', ranked $11 / 48$ in Table 1, while creativity was only found in $4.7 \%$ of the courses.

It should be kept in mind that comparing these works is not straightforward. Aasheim et al. were ranking what they call 'non-technical skills' identified by U.S. IT managers almost a decade ago. Stevens and Norman, although more recent, were looking at data from New Zealand only, and their job advertisement data only includes those ads that listed two or more soft skills. Nonetheless, broad trends such as the importance of communication and teamwork are apparently robust to different methodologies.

\subsection{RQ2: What types of courses?}

Our second research question was: What types of non-technical courses are included in undergraduate computing programs? We also asked: What percentage of these courses are compulsory, in what year are they offered, and what percentage of them have explicit learning outcomes mentioning soft skills?

All courses are grouped into eight categories, as visible in Table 4 , along with the percentage of programs offering that type of course (\% Prog.), the percentage that are compulsory (\%Compul.), the mean amount of ECTS credits received, the mean year they are offered in, and the percentage that have explicit learning outcomes mentioning soft skills (\%ELO). On average, courses take place in year 2, while students can earn 5.6 credits, of which $20.8 \%$ is optional.

Project based courses being 'Software Engineering Team Project' and 'Development project' harbour popular skills such as teamwork, set/keep timelines and presentation skills. This is both the biggest group and the heaviest in terms of credits, and is almost always compulsory.

Humanities based skills are ethics, critical thinking, and role awareness. This broad category represents courses such as 'Philosophy', 'Ethics in computing', and 'Social aspects of IT'.

Business based top skills include teamwork, presentation skills, and leadership. Examples of typical business courses are 'Project management' and 'Entrepreneurship'. About half of the courses are optional, and these are usually taught in the later years.

Communication based skills are oral and written communication, presentation skills, and giving/receiving feedback. 'Public Speaking' and 'Writing skills' are example courses of this category.

Coaching related top skills are role awareness, ethics, and coaching itself. Smaller introductory courses such as 'Techniques of cooperative work' and 'Studying at the University' are taught early in the program as these help students successfully graduate.

Professional skills include teamwork, oral and written communication, and self-reflection. Courses entitled 'Professional Computing Practice' and 'Transferable skills' are very interesting to look at from a non-technical skill perspective, and are mostly compulsory.

Seminar based courses being 'Selected chapters of Computer Science' and 'Enterprise Seminar' teach presenting, adjusting your communication to the audience, and written communication. As visible in the mean credits, these are typically lightweight modules.

Table 3: Soft skills identified in this search and the percentage of courses $(n=278)$ including each skill.

\begin{tabular}{lr}
\hline Skill & $\%$ \\
\hline Communication (written, oral) & $47.1(25.9,21.2)$ \\
Teamwork & 34.2 \\
Ethics & 26.6 \\
Presentation skills & 25.5 \\
Role awareness & 17.6 \\
Critical thinking & 16.2 \\
Set/keep timelines & 15.5 \\
Self-reflection & 12.6 \\
Adjust communication to audience, & \\
Give/receive feedback, Problem solving, & \\
Conflict resolution, Leadership, & \\
Self-directed learning, Accountability, & \\
\hline
\end{tabular}

Effectively searching for data 
Table 4: \% of programmes offering courses in each category, $\%$ that are compulsory, average credits \& year offered, and \% with explicit learning outcomes (ELO).

\begin{tabular}{lrrrrr}
\hline Category & \%Prog. & \%Compul. & $\overline{\text { Credits }}$ & $\overline{\text { Year }}$ & \%ELO \\
\hline Project & 31 & 93 & 7.8 & 2.1 & 37 \\
Humanities & 21 & 88 & 4.8 & 1.9 & 28 \\
Business & 13 & 54 & 5.0 & 2.3 & 35 \\
Communication & 10 & 66 & 4.0 & 2.0 & 28 \\
Coaching & 9 & 81 & 4.1 & 1.6 & 50 \\
Professional & 9 & 96 & 5.1 & 2.1 & 44 \\
Seminar & 3 & 66 & 3.0 & 2.3 & 11 \\
Art-creativity & 1 & 75 & 5.8 & 1.7 & 0 \\
\hline
\end{tabular}

Lastly, Art-creativity houses skills such as creativity itself, critical thinking, and intercultural skills. The courses entitled 'Bridging Arts and Technology' and 'Creative Coding' sound very alluring to us, even if barely $1 \%$ of the programs offer such a course.

Only $33.7 \%$ of the courses explicitly mention skills in the learning outcomes, besides the requirement of pure knowledge-based attributes. Considering that we only included non-technical courses, as explained in Section 3 , this is an alarmingly low rate. Many learning outcomes are in bad shape and contain nothing more than a few general sentences that make it hard for us as researches to analyse and for students to judge what is expected of them.

\section{Online Data and Resource}

We created an interactive website for the community, available at https://people.cs.kuleuven. be/ wouter. groeneveld/courses/, to explore and visualise the data using a geographical map of Europe (see Figure 1), containing all data and results presented here (and more). The data can be searched, filtered, and links to all syllabi are provided.

A compiled selection of noteworthy courses for each category from Section 4.2 is also available online, together with help and information pages, as well as the ability to download the raw data.

\section{THREATS TO VALIDITY}

Our study is not without threats to its validity. First, we intentionally only included European universities for three primary reasons, which we detailed in Section 3:

1. We wanted to get a representative picture, free from biases such as dominating US institutions.

2. Europe is largely unified by the Bologna accord Fuller et al. (2006) and Becker and Fitzpatrick (from which our methodology is derived) found that European institutions report learning outcomes explicitly (as the Bologna accord mandates).

3. Scale, relevance and expertise. The authors work and teach in different European countries and thus, this is where they are most interested, and familiar, resulting in a manageable, yet representative data set.

Another threat to validity is that our results are based on world rankings. We chose this for several reasons, many of which were justified by Becker and Fitzpatrick Becker and Fitzpatrick (2019) whose method we adapted:

1. Using rankings for similar purposes has been used successfully before, e.g. Guo (2014); Becker and Fitzpatrick (2019).

2. These particular rankings favour research institutions. Although Becker and Fitzpatrick found this to be a threat, we feel that the benefits of this approach outweigh such threats. Additionally, how researchintensive institutions teach soft-skills is valuable information provided the source of data is kept to mind.

3. Using rankings does give a repeatable and not-biased-by-the-researcher method of sampling institutions.

Becker and Fitzpatrick also noted language difficulties as a problem that affected their sampling. Although we were not immune to this, limiting our search to Europe, and the fact that one of the authors is able to read four European languages, is a mitigating factor. 
Another possible threat is that the list of identified skills for each course is incorrect or that some of the concepts from the learning outcomes are misinterpreted. To minimise this risk, a data validation step was added, as detailed in Section 3. The reliance on Google Translate for certain languages might also influence the skill list. Further data retrieval difficulties, as explained in Section 4, caused us to exclude some institutions. However, as these were replaced, a consistent ratio of universities for each country was maintained.

\section{CONCLUSION}

The main contribution of this work is the finding that non-technical skills are being addressed by computing curricula in Europe, to a fairly considerable degree. Further we provide a report and web resource detailing what soft skills are present in European curricula, and where. Equally importantly, we present data on what skills are infrequently taught. Additionally, we find that the skills being addressed match prior work reporting on industry requirements - something we consider to be a positive development. Until now, however, this landscape may not have been apparent and there was no clear and large-scale picture of which skills are actually being taught, on what level, and in which courses.

The two most commonly occurring skills found in literature - communication and teamwork - are consistently present in our results. Together with ethics and presentation skills, they form a strong and seemingly wellimplemented core of non-technical skills in European computing curricula. It is perhaps equally interesting to investigate the other end of the spectrum, where skills/traits such as creativity and empathy are severely underrepresented.

We hope that our work can help the community make better-informed decisions about what to include (or not include) in their future local curricula during new course design or existing course review.

\section{References}

Cheryl Aasheim, Jordan Shropshire, Lixin Li, and Christopher Kadlec. 2012. Knowledge and skill requirements for entry-level IT workers: A longitudinal study. Journal of Information Systems Education 23, 2 (2012), 193.

Cheryl L Aasheim, Susan Williams, and E Sonny Butler. 2009. Knowledge and skill requirements for IT graduates. Journal of Computer Information Systems 49, 3 (2009), 48-53.

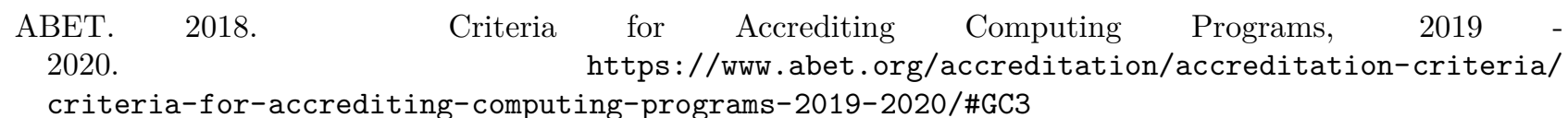

Simon C Barrie. 2012. A research-based approach to generic graduate attributes policy. Higher Education Research 83 Development 31, 1 (2012), 79-92.

Brett A Becker and Thomas Fitzpatrick. 2019. What Do CS1 Syllabi Reveal About Our Expectations of Introductory Programming Students?. In Proceedings of the 50th ACM Technical Symposium on Computer Science Education. ACM, 1011-1017.

Ursula Fuller, Arnold Pears, June Amillo, Chris Avram, and Linda Mannila. 2006. A Computing Perspective on the Bologna Process. In Working Group Reports on ITiCSE on Innovation and Technology in Computer Science Education (ITiCSE-WGR '06). ACM, New York, NY, USA, 115-131. https://doi.org/10.1145/ 1189215.1189181

Wouter Groeneveld, Joost Vennekens, and Kris Aerts. 2019. Software Engineering Education Beyond the Technical: A Systematic Literature Review. In Proceedings of the 47th Annual SEFI Conference. SEFI, $1607-1622$.

Philip Guo. 2014. Python is Now the Most Popular Introductory Teaching Language at Top US Universities. Communications of the ACM Blog (BLOG@CACM), July (2014).

Matthew Hertz. 2010. What Do "CS1" and "CS2" Mean? Investigating Differences in the Early Courses. In Proceedings of the 41st ACM Technical Symposium on Computer Science Education (SIGCSE '10). Association for Computing Machinery, New York, NY, USA, 199-203. https://doi.org/10.1145/1734263.1734335

Christopher D. Hundhausen, Anukrati Agrawal, and Pawan Agarwal. 2013. Talking About Code: Integrating Pedagogical Code Reviews into Early Computing Courses. Trans. Comput. Educ. 13, 3, Article 14 (Aug. 2013), 28 pages. https://doi.org/10.1145/2499947.2499951 
Association for Computing Machinery (ACM) Joint Task Force on Computing Curricula and IEEE Computer Society. 2013. Computer Science Curricula 2013: Curriculum Guidelines for Undergraduate Degree Programs in Computer Science. Technical Report. New York, NY, USA. 999133.

Damien Joseph, Soon Ang, Roger H. L. Chang, and Sandra A. Slaughter. 2010. Practical Intelligence in IT: Assessing Soft Skills of IT Professionals. Commun. ACM 53, 2 (Feb. 2010), 149-154. https://doi.org/ 10.1145/1646353.1646391

Päivi Kinnunen, Matthew Butler, Michael Morgan, Aletta Nylen, Anne-Kathrin Peters, Jane Sinclair, Sara Kalvala, and Erkki Pesonen. 2018. Understanding initial undergraduate expectations and identity in computing studies. European Journal of Engineering Education 43, 2 (2018), 201-218.

Paul Luo Li, Amy J Ko, and Jiamin Zhu. 2015. What makes a great software engineer?. In Proceedings of the 37th International Conference on Software Engineering-Volume 1. IEEE Press, 700-710.

David López, Fermín Sánchez, Josep-Llorenç Cruz, and Agustín Fernández. 2007. Developing non-technical skills in a technical course. In 2007 37th Annual Frontiers In Education Conference-Global Engineering: Knowledge Without Borders, Opportunities Without Passports. IEEE, F3B-5.

Miriam L Matteson, Lorien Anderson, and Cynthia Boyden. 2016. "Soft Skills": A Phrase in Search of Meaning. portal: Libraries and the Academy 16, 1 (2016), 71-88.

The IEEE CS / ACM Interim Joint Task Force on Computing Curricula. 2008. Computer Science Curriculum 2008: An Interim Revision of CS 2001. https://www.acm.org/binaries/content/assets/education/ curricula-recommendations/computerscience2008.pdf

The IEEE CS / ACM Joint Task Force on Computing Curricula. 2001. Computing Curricula 2001, Computer Science. https://www.acm.org/binaries/content/assets/education/curricula-recommendations/ cc2001.pdf

Sandeep Purao and Hoi Suen. 2010. Designing a Multi-faceted Metric to Evaluate Soft Skills. In Proceedings of the 2010 Special Interest Group on Management Information System's 48th Annual Conference on Computer Personnel Research on Computer Personnel Research (SIGMIS-CPR '10). ACM, New York, NY, USA, 88-91. https://doi.org/10.1145/1796900.1796934

Russell W Rumberger. 1989. Assessing Work Skills: Conceptual and Methodological Issues. Center for Educational Research at Stanford, School of Education, Stanford University.

Matt Stevens and Richard Norman. 2016. Industry Expectations of Soft Skills in IT Graduates: A Regional Survey. In Proceedings of the Australasian Computer Science Week Multiconference (ACSW '16). ACM, New York, NY, USA, Article 13, 9 pages. https://doi.org/10.1145/2843043.2843068

Guangzhi Zheng, Chi Zhang, and Lei Li. 2015. Practicing and Evaluating Soft Skills in IT Capstone Projects. In Proceedings of the 16th Annual Conference on Information Technology Education (SIGITE '15). ACM, New York, NY, USA, 109-113. https://doi.org/10.1145/2808006.2808041 